Document downloaded from:

http://hdl.handle.net/10251/64118

This paper must be cited as:

González Altozano, P.; Gasque Albalate, M.; Ibáñez Solís, F.; Gutiérrez-Colomer, RP. (2015). New methodology for the characterisation of thermal performance in a hot water storage tank during charging. Applied Thermal Engineering. 84:196-205. doi:10.1016/j.applthermaleng.2015.03.048.

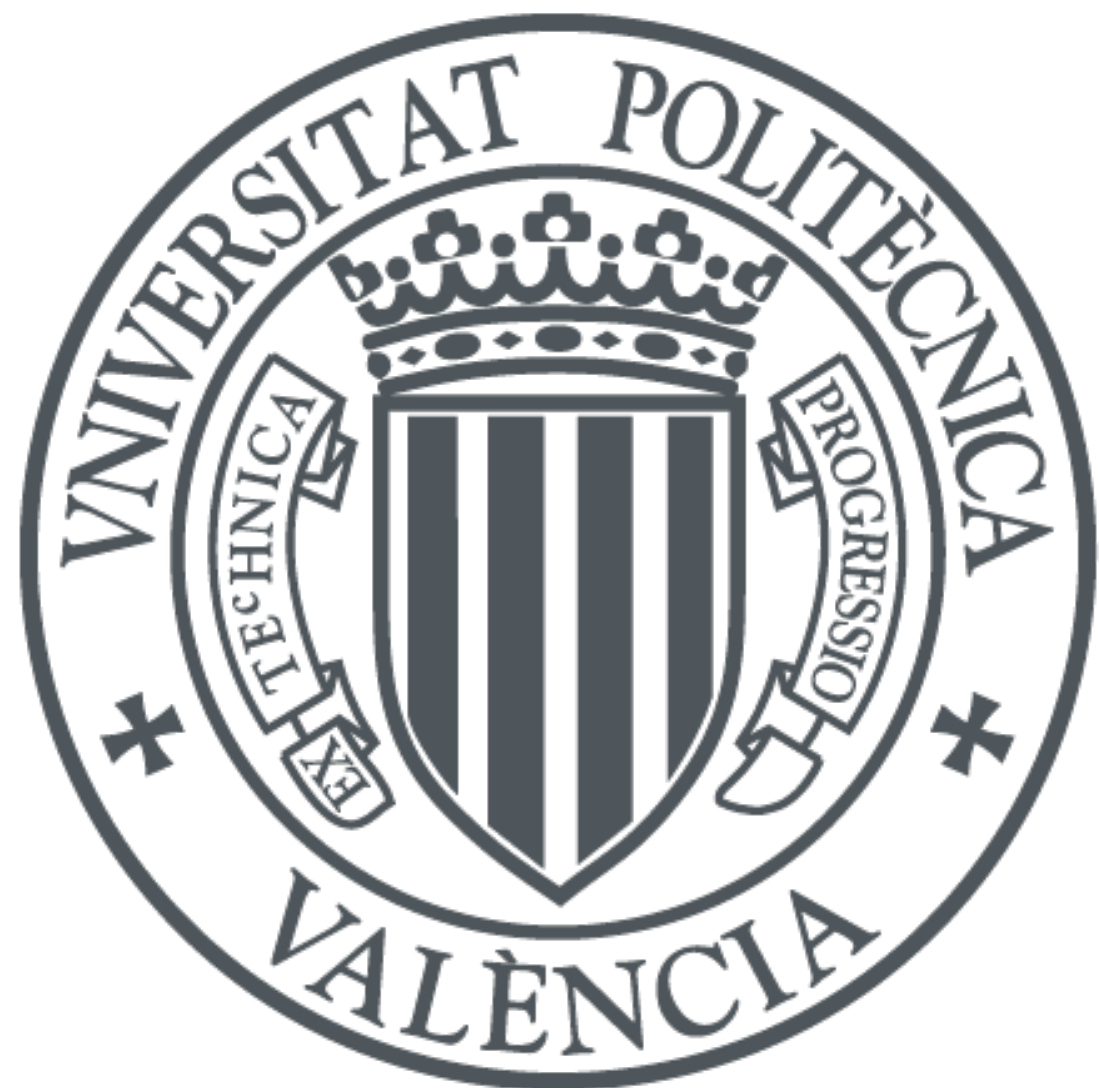

The final publication is available at

https://dx.doi.org/10.1016/j.applthermaleng.2015.03.048

Copyright Elsevier

Additional Information 


\section{NEW METHODOLOGY FOR THE CHARACTERISATION OF THERMAL PERFORMANCE IN A HOT WATER STORAGE TANK DURING CHARGING}

Pablo González-Altozano ${ }^{1}$, María Gasque ${ }^{2}$, Federico Ibáñez ${ }^{1}$, Rosa Penélope Gutiérrez-

Colomer $^{1}$

Universitat Politècnica de València. Camino de Vera s/n. 46022 Valencia (Spain)

${ }^{1}$ Dept. Ingeniería Rural y Agroalimentaria. e-mail: pgaltozano@agf.upv.es

2 Dept. Física Aplicada.

\section{ABSTRACT}

In solar water heating systems, the application of certain stratification indices requires the characterisation of the water temperature distribution profile inside the tank and its evolution. In order to avoid the limitations and drawbacks related to the discrete measures provided by experimental trials, this paper presents a newly developed method, called Virtual TC, which allows the water temperature to be estimated at any depth and at any time in a storage tank during the charge process. The proposed methodology can be very useful for estimating the numerous temperature-dependent indices employed for the characterisation and evaluation of thermal stratification in water storage tanks. As a practical example, it was successfully applied to determine the instantaneous temperature profile and thermocline thickness and its evolution throughout charging.

It is concluded that the Virtual TC method gives highly satisfactory results under normal operational conditions for a hot water storage tank during the charge cycle.

Keywords: thermal energy storage, curve fitting, five-parameter logistic function, stratification indices, temperature profile, thermocline thickness evolution. 


\section{INTRODUCTION}

In solar water heating systems, water is always heated as it flows through the solar collector to then be conducted to an energy storage device, generally a hot water storage tank. The storage device plays a key role in such facilities, as the timing of the availability and demand for thermal energy do not often coincide.

Thermal water stratification takes place in the storage tank due to the difference in density between hot and cold water. The denser cold water falls to the bottom of the tank, while less dense hot water rises to the top. The region with the steepest temperature gradient separating the hot and cold fluid regions in the tank is called the thermocline [1].

The mixing of cold and hot water is minimised in a well stratified tank, thereby achieving good discharge efficiency. Hence stable thermal stratification in the water tank must be promoted, improved and maintained to enhance the effectiveness of thermal storage and, consequently, overall system performance [2-4].

The characterisation and evaluation of thermal stratification has been the subject of numerous research works (see the reviews by Han et al. and Shukla et al. $[5,6]$ ) and there are a significant number of studies that address this issue both numerically and experimentally. As show recent investigations using three-dimensional unsteady CFD models [7,8], numerical approaches provide very detailed insights and understanding of the physical phenomenon. Nevertheless, the CFD approach has the drawback of requiring a great use of computational resources and time even if a one-dimensional CFD model is used, compared with analytical logistic models [9].

Many methods and parameters have been proposed for estimating stratification efficiency, or to evaluate the level of stratification during charging, storing and discharging. Thus, Haller et al. [10] reviewed different methods proposed for characterising thermal stratification in energy storage during charging, storing and discharging in several theoretical cases. Castell et al. [11] studied and compared the suitability and performance of different experimental working conditions during discharge, and the most widely used dimensionless numbers to characterise thermal stratification in water tanks, while Mawire and Taole [12] compared and evaluated six thermal stratification parameters under experimental charging conditions.

In many cases, the application of certain indices or numbers used to evaluate the stratification necessarily requires the characterisation of the temperature distribution profile inside the tank and its evolution over time (see the classification and summaries of such numbers in $[1,10,13]$ ). There are also some methods for evaluating and comparing stratification efficiencies based on the thermocline gradient or the thickness of the thermocline region [10] which have been used in many studies to assess the degree of stratification in a tank [14-17].

In experimental trials, however, the installation of vertical arrays of temperature sensors distributed uniformly with a certain spacing to provide discrete temperature data is quite usual. To ensure that the instantaneous temperature profiles obtained from discrete data records are useful for studing the thermal performance of the water tank, the space between the sensors must be equal to or lesser than thermocline thickness [15]. Hence, and for instance, the discontinuous temperature distribution profiles that are formed from discrete temperature data cannot be used to accurately determine thermocline thickness, given the ambiguity while defining its limit points [18].

In order to avoid the limitations and drawbacks of such discrete measures as well as those already mentioned derived from the numerical approaches, this paper presents a new method, called Virtual TC, which allows water temperature to be estimated at any depth and at all times in a storage tank during the charge process. For this purpose, the evolution of the water temperature distribution profile in a hot water storage tank was modelled during the charge 
process. For such modelling, an approximating function was selected which had the smallest number of parameters and most closely fitted the experimental data: the five-parameter logistic (5PL) curve. The experimental and estimated temperature values were compared and the results showed that the 5PL function came very close to the experimental data.

The Virtual TC method can prove very useful in the study of thermal performance and the determination of several of the indices used to quantify the stratification efficiency of thermal energy storage tanks. By way of example, this method was applied to the characterisation of the instantaneous temperature profile and the estimation of thermocline thickness under different experimental conditions, which proved its excellent suitability and usefulness.

\section{MATERIALS AND METHODS}

\subsection{Facility and experimental trials}

Experimental trials were conducted in a facility provided with a 905-L cylindrical hot water storage tank ( $800 \mathrm{~mm}$ inner diameter, 1,800 $\mathrm{mm}$ high). The side walls, top and bottom were covered with a $50-\mathrm{mm}$-thick layer of insulating material (fibreglass) with a thermal conductivity of $0.043 \mathrm{~W} \cdot \mathrm{m}^{-1} \cdot \mathrm{K}^{-1}$. The overall heat transfer coefficient through the tank walls at experimental conditions was between 5 and $8 \mathrm{~W} \cdot \mathrm{K}^{-1}\left(5.77 \mathrm{~W} \mathrm{~K}^{-1}\right.$ on average). Two different and independent inlets were arranged at the top of the tank symmetrically to its vertical axis: a conventional inlet elbow (E) and a sintered bronze conical diffuser (SBCD).

In order to record the water temperature in the tank, 12 type T (Class 1 ) thermocouples (TC) were distributed uniformly along the vertical axis of the tank $(150 \mathrm{~mm}$ apart and $75 \mathrm{~mm}$ from both the top and bottom of the tank). Similarly, two more TCs were used to record the water inlet and outlet temperatures during the charge process.

Two thermostatted tanks, with hot and cold water respectively, were used to ensure a constant temperature of the inlet water supply to the storage tank. A fourth tank was also employed to store the output water from the experimental tank during the trials. The water flow was measured at the tank entrance with an electromagnetic flowmeter (Endress Hauser mod. Promag $53 \mathrm{H} 08 \mathrm{DN} 8$ error $< \pm 0.2 \%$ ). Constant flow was guaranteed by a pump with a variable speed drive (Altivar 61) controlled by a flowmeter signal as an input. A schematic view of the experimental setup is shown in Fig. 1.

The signal of each sensor was recorded by means of the Compact DAQ 9178 data acquisition system by National Instruments (NI) with an NI-9213 module (16-ch, 24 bits) for thermocouple signal conditioning and acquisition, and an NI-9208 module (16-ch mA, 24 bits) for flowmeter signal acquisition. Signals were captured, displayed and recorded by software compiled in Labview (NI) every $10 \mathrm{~s}$. The TC temperatures with all the acquisition system were calibrated against a PT100 (error $< \pm 0.1 \%$ ). Figure 2 provides a picture of the experimental facility, described in more detail in [19].

Four thermal charging tests (Table 1) were carried out with the two inlet devices, E and SBCD, at two water flow rates: high $\left(\mathrm{H}, 16 \mathrm{~L} \cdot \mathrm{min}^{-1}\right)$ and low $\left(\mathrm{L}, 6 \mathrm{~L} \cdot \mathrm{min}^{-1}\right)$. The water tank temperature was $20 \pm 0.2^{\circ} \mathrm{C}$ at the start of each trial. In all cases, water at a constant flow rate was injected from the tank thermostatted to $52 \pm 0.2^{\circ} \mathrm{C}$ until $120 \%$ of the total storage tank volume was replaced. Charge duration was expressed as a dimensionless time $\left(t^{*}\right)$, which was determined as follows:

$\mathrm{t}^{*}=\frac{\text { flow }\left(\mathrm{L} \cdot \mathrm{s}^{-1}\right) \cdot \text { time }(\mathrm{s})}{\text { tank volume }(\mathrm{L})}$ 
Therefore, the dimensionless time was deemed to equal 1 when the time needed to replace the total tank volume with the water flow used in each trial had elapsed.

The recorded data were processed with the Matlab-implemented programmes [20], which also provided a graphic representation of the results.

The effect of the performance of the two inlet devices (SBCD and elbow), water flow rate and the turbulence created, was studied in detail in [19]. At the end of the charge period, the temperatures registered by the thermocouples located at the top and in the middle part of the tank were verified to be lower with the elbow than with the SBCD, indicating a greater degree of mixing during thermal charging. This effect was more pronounced when the input flow was higher, and it was especially noticeable at the top of the tank. In the case of the elbow, the temperature rose more slowly as the flow increased, but even by the end of the charge period it did not reach the value of the inlet temperature, demonstrating the destratifying effect produced by a higher flow. In the case of the SBCD, and at both the top and in the middle region, the flow did not significantly affect stratification and the temperatures were the same regardless of flow rate as the charge process was finishing.

In the tests carried out with the elbow, the increase in temperatures first started in the middle and lower regions of the tank. This result, together with the thicker thermoclines observed, indicated a greater degree of mixing. Moreover, the increase in temperature in the lower part of the tank caused the hot water to leave the tank first; thus, the efficiency of the installation was affected negatively.

The results showed that a higher thermal stratification, which was also stable throughout the charge period studied, was achieved using the SBCD inlet for all flows tested. In contrast, the loss of thermal stratification was largely influenced by the flow in the case of the elbow.

The fluctuations in the temperature due to the turbulence created by the water inflow were greater when water came through the elbow, being higher at the higher flow. Moreover, they were virtually negligible when the water entered through the SBCD. The fluctuations in this signal indicated the degree of mixing in the tank due to the hot water inflow, and were related to the speed at which the temperature of the first thermocouple increased. The lower the fluctuations, the faster this temperature increased, indicating less mixing of the water inside the tank.

In view of these results, it seems that the evolution of the temperatures registered by the thermocouples can be used to qualitatively compare the effect of different inlet devices on thermal energy storage tanks.

\subsection{Temperature evolution during a trial and the selection of an approximating function}

The characteristic trend of the temperature evolution recorded by each TC against the dimensionless time during a trial was sigmoidal (S-shaped) and is shown in Fig. 3, where the SBCD-L trial is used as an example.

In order to model the temperature evolution in each TC, an approximating function or curve model should be previously selected. Various authors have used a logistic curve to describe the thermal behaviour of a storage tank $[9,21]$. The approximating function must be adequate to detect the variations of the true curve with the smallest number of parameters. Since in this work the pattern obtained experimentally was slightly asymmetric, the four-parameter logistic (4PL) function described by the Equation (1) did not fit the data very well.

$$
T\left(t^{*} ; a, b, c, d\right)=a+\frac{b-a}{\left(1+\left(\frac{t^{*}}{c}\right)^{d}\right)}
$$


where $\mathrm{T}$ is the estimated temperature, $\mathrm{t}^{*}$ is the dimensionless charging time, $\boldsymbol{a}$ and $\boldsymbol{b}$ are the lower and upper asymptotes respectively, $\boldsymbol{c}$ is the inflection point and $\boldsymbol{d}$ is the slope factor.

In order to correct this shortcoming, the 4PL model was extended by adding a fifth parameter, $\boldsymbol{g}$, which quantified the asymmetry and improved then the quality of the fit. Thus, in this work, the five-parameter logistic (5PL) curve, given by Equation (2), was chosen. It should be noted that other formulations of the 5PL function were also tried as curve models: with the fiveparameter logistic-two slopes [22], with two slope parameters, and with the Richards function [23]. Nevertheless, the 5PL function worked better and it appeared to be the most general and versatile model as it met the particular requirements of the case being studied. This function is commonly applied for curve fitting analysis in bioassays or immunoassays to model doseresponse data, which also presents a sigmoid shape and asymmetry [24,25].

The 5PL model provides an excellent compromise between overparametrised models that can fit data closely at the expense of substantial variance in predictions, and underparametrised models that involve major lack-of-fit errors (the curve model may not approach the true curve properly, although the number of data has increased). This is because the lowest number of parameters that any general asymmetric sigmoidal function can possess is five: one for the upper asymptote, one for the lower asymptote, one related to the overall length of the function's transition region, one related to the location of the transition region and one related to the degree of asymmetry [25].

The general form that the 5PL function takes is:

$$
T\left(t^{*} ; a, b, c, d, g\right)=a+\frac{b-a}{\left(1+\left(\frac{t^{*}}{c}\right)^{d}\right)^{g}}
$$

When applied to estimate the temperature of one TC $(T)$ versus the dimensionless charging time $\left(t^{*}\right)$, the parameters acquire the following meanings:

$\boldsymbol{a}$ is the temperature of the lower asymptote (temperature in the TC at the beginning of the experimental trial);

$\boldsymbol{b}$ is the temperature of the upper asymptote (temperature in the TC at the end of the experimental trial);

$c$ is the dimensionless time position of the transition region (dimensionless time of the inflection point);

$\boldsymbol{d}$ is the slope of the curve's transition region (this parameter controls the rapidity of the curve's transition between asymptotes); and,

$\boldsymbol{g}$ is the asymmetry factor. This parameter, jointly with $\boldsymbol{d}$ controls the approach rate to the $\boldsymbol{a}$ asymptote, and permits asymmetry to be effectively modelled. A value of $g=1$ represents perfect symmetry around the inflection point, and the 5PL equation is identical to the $4 \mathrm{PL}$ equation.

With this model, the temperature evolution throughout thermal charging at all 12 TC installed in the tank is independently fitted.

\subsection{Curve fitting}

The goal of curve fitting is to find the set parameter values of the 5PL function that best approach the experimental data, which thus, minimise the deviations between the observed and expected 
temperature values at each TC. For this purpose, the Matlab function Isqcurvefit was used [20]. This Matlab function is based in the trust-region-reflective algorithm and the curve fit is calculated by an iterative procedure, which starts by initially guessing the unknown parameter values supplied with the equation. During each iteration, the Matlab function varies the parameter values slightly until it finds the best fit.

For this fit, it was verified that it was appropriate to fix the values of some of the parameters. In the tests performed at low flow, or when the inlet device promotes stratification, the temperature evolution in each TC follows a similar and characteristic trend (an example is found in Fig. 3, the trial SBCD-L). In these cases, it is advisable and sufficient to fix the temperature of both the lower and upper asymptotes (parameters $\boldsymbol{a}$ and $\boldsymbol{b}$ ) for a correct fit.

However, this is not favourable for fits in other cases; for instance, when temperature evolution is not the same for all the TCs, as in the $\mathrm{E}-\mathrm{H}$ trial (water inlet through the elbow with high flow; see Fig. 4). In the $\mathrm{E}-\mathrm{H}$ trial, the inlet device generated a greater mix and thermal destratification at the top of the tank. So, it is advisable to fix not only parameters $\mathbf{a}$ and $\boldsymbol{b}$, but also parameter $\boldsymbol{c}$ of the dimensionless time of the inflection point.

Figure 5, with the $\mathrm{E}-\mathrm{H}$ trial, illustrates the difference in the values of the parameters that integrate the logistic equation by exclusively fixing parameters $\boldsymbol{a}$ and $\boldsymbol{b}$ (Fig. 5, left) or by also fixing parameter $\boldsymbol{c}$ (Fig. 5 , right). If parameter $\boldsymbol{c}$ is not fixed, parameters $\boldsymbol{d}$ and $\boldsymbol{g}$ may diverge showing sudden oscillations without a well-defined trend. A range of values was therefore established to control this divergence: $[0,20]$ for paramener $\boldsymbol{g}$, and $[-50,0]$ for parameter $\boldsymbol{d}$ (Fig. 5 , left). Thus, parameters $\boldsymbol{g}$ and $\boldsymbol{d}$ remained within the value range set for them. If parameter $\mathbf{c}$ is fixed, parameters $\boldsymbol{g}$ and $\boldsymbol{d}$ present a well-defined trend without oscillations. Thus, in the four trials conducted in this work, the values of parameters $\boldsymbol{a}, \boldsymbol{b}$ and $\boldsymbol{c}$ were fixed.

The Isqcurvefit function does not set the parameters at an exact value, although it is possible to implement them as a very small range of variation. For this reason, for the initial guess of the values of fixed parameters $\boldsymbol{a}, \boldsymbol{b}$ and $\boldsymbol{c}$, the interval $\left[\mathrm{v}_{\mathrm{i}}, \mathrm{v}_{\mathrm{i}}+0.0001\right]$ was supplied, with $\mathrm{v}_{\mathrm{i}}$ being the minimum value allowed for these parameters.

Table 2 shows the initial values and the variation range of the five parameters used for the fit of the 5PL function at each TC and in the four experimental trials.

Parameter $\boldsymbol{a}$ at each curve was set at interval $\left[\mathrm{T}_{\text {ini, }} \mathrm{T}_{\mathrm{ini}}+0.0001\right]$, with $\mathrm{T}_{\mathrm{ini}}\left({ }^{\circ} \mathrm{C}\right)$ being the first temperature value recorded by each TC (the lowest recorded one).

Parameter $\boldsymbol{b}$ was set at interval $\left[T_{f}, T_{f}+0.0001\right]$, with $T_{f}\left({ }^{\circ} \mathrm{C}\right)$ being the last temperature value recorded by each TC (the highest recorded one).

Parameter $\boldsymbol{c}$ of the adjusted curve at the position of each TC corresponded to the dimensionless time at which the water volume replaced during thermal charging reached the depth where the TC was installed. As expected, the temperature transition region between the hot and cold zones of the water tank is found at this point. In the test facility, the values of parameter $c$ (expressed in accordance with the dimensionless depth at which each TC was located, $\mathrm{Z}_{\mathrm{TC}}$ ) were as follows, ranked in order from the most superficial TC to that situated at greatest depth: $1 / 24,3 / 24,5 / 24$, $7 / 24,9 / 24,11 / 24,13 / 24,15 / 24,17 / 24,19 / 24,21 / 24$ and 23/24.

With parameters $\boldsymbol{a}, \boldsymbol{b}$ and $\boldsymbol{c}$ fixed, the Matlab Isqcurvefit function was run to check goodness of fit. If the algorithm did not provide a satisfactory solution, it was also possible to limit the variation range enabled for the other two parameters ( $\boldsymbol{d}$ and $\boldsymbol{g}$ ) so that the solution did not diverge. Another option consisted of testing those $\boldsymbol{d}$ and $\boldsymbol{g}$ values corresponding to the curves with a good fit, taken as the initial values for all the other curves. It was verified that the satisfactory mean fit values gave a good result. However if $\boldsymbol{a}, \boldsymbol{b}$ and $\boldsymbol{c}$ were fixed, it would be quite likely that $\boldsymbol{d}$ and $\boldsymbol{g}$ converged correctly, with acceptable values. 
Experimental data for the temperature profile evolution of the $12 \mathrm{TC}$, together with the fitting profile obtained with the 5PL function, are shown in Figure 6 (SBCD-L trial) and Figure 7 (E-H trial).

For the purpose of assessing the performance accuracy of the 5PL function when estimating temperature evolution, Pearson's correlation coefficient was obtained according to Equation (3):

$r=\frac{n \sum x_{i} \hat{x}_{i}-\left(\sum x_{i}\right)\left(\sum \hat{x}_{i}\right)}{\sqrt{n\left(\sum x_{i}^{2}\right)-\left(\sum x\right)^{2}} \sqrt{n\left(\sum \hat{x}_{i}^{2}\right)-\left(\sum \hat{x}_{i}\right)^{2}}}$

where $x_{i}$ and $\hat{X}_{i}$ are the experimental and estimated values of $T$, respectively, and $n$ is the number of observations.

Moreover, the Root Mean Squared Error $\left(\mathrm{RMSE},{ }^{\circ} \mathrm{C}\right)$, given by Equation (4), was calculated to introduce a relative measure of error.

$$
\text { RMSE }=\left(\frac{1}{n} \cdot \sum_{i=1}^{n}\left(x_{i}-\hat{x}_{i}\right)^{2}\right)^{0.5}
$$

The evolution of the values which the five 5PL function parameters successively took at each TC position showed a well-defined tendency. This enabled the value of each parameter between two successive TCs to be interpolated.

To perform this interpolation, the spline function of Matlab was used, which provides the piecewise polynomial form of the cubic spline. A cubic spline function is defined as piecewise polynomials of degree three. The pieces join in the so-called knots and fulfil the continuity conditions of the function itself, and of the first and second derivatives [26]. In this case, knots are located at each data point so that no arbitrary decisions are required. In this way, a cubic spline was obtained for each parameter, which estimated the value of this parameter at the desired depth. Figure 8 presents the values of the five 5PL function parameters and the interpolation with the spline using the SBCD-L trial as an example. The interpolation with the spline allows the fit of the 5PL function to be determined at any point.

This method, which permits temperature to be determined at any depth and at any time during the charge cycle, is called Virtual TC.

\subsection{Applying Virtual TC: instantaneous temperature profile and thermocline thickness}

With a view to demonstrating the usefulness of the method, the Virtual TC method was applied, by way of example, to characterise the instantaneous temperature profile and to estimate the thermocline thickness of the four experimental trials performed in the present work.

In a stratified tank, thermocline thickness can be an indicator of the degree of stratification. The thermocline thickness region can vary hugely in accordance with operating temperatures, flow rate and diffuser design [27]. Although a thicker thermocline is associated with a higher degree of stored energy degradation, thermocline thickness does not provide a quantitative measure of the extent of this degradation [1]. This measure has also been reported as having a restricted application because it cannot be used if the inlet temperature is variable $[1,16,28]$.

Musser and Bahnfleth [15] proposed a methodology to obtain thermocline thickness, which was adopted in the present work. According to this method, thermocline thickness was defined in relation to a dimensionless temperature $\Theta$, with $\Theta=\left(T-T_{c}\right) /\left(T_{h}-T_{c}\right)$. For the charge cycle, $T_{c}$ is the average inlet temperature and $T_{h}$ is the initial bulk temperature. The dimensionless temperature varies from zero on the cool side of the thermocline, to a maximum of one on the 
warm side. Thermocline thickness was estimated at a given instant as the region between the two cut-off points in the temperature profile for which $\Theta=0.9$ and $\Theta=0.1$, respectively. In this way, the thermocline thickness is defined by discarding $10 \%$ of the total difference at each end of the temperature profile. Thus, in the present study, the thermocline thickness was determined by considering $80 \%$ of the overall temperature gradient region.

\section{RESULTS AND DISCUSSION}

\subsection{Fitting the 5PL function}

The performance accuracy of the 5PL function in the temperature evolution estimation was very good. In the trials performed with SBCD, the RMSE values for low flow ranged between $0.2065^{\circ} \mathrm{C}$ and $0.3525^{\circ} \mathrm{C}$, with an average value of $0.2374^{\circ} \mathrm{C}$. For high flow, the RMSE values ranged between $0.2726^{\circ} \mathrm{C}$ and $0.4861^{\circ} \mathrm{C}$, with an average value of $0.4197^{\circ} \mathrm{C}$. In the trials carried out with the elbow, the RMSE values ranged from $0.2500^{\circ} \mathrm{C}$ to $0.6934^{\circ} \mathrm{C}$ (average value: $0.5075^{\circ} \mathrm{C}$ ), and between $0.5358^{\circ} \mathrm{C}$ and $1.1627^{\circ} \mathrm{C}$ (average value: $0.9523^{\circ} \mathrm{C}$ ) for low and high flow, respectively. On average, Pearson's correlation coefficient $r$ was 0.9997 and 0.9995 in the SBCD-L and SBCD$\mathrm{H}$ trials, while it was 0.9992 and 0.9966 in the $\mathrm{E}-\mathrm{L}$ and $\mathrm{E}-\mathrm{H}$ trials, both respectively. In sum, the coefficient $r$ value was higher than 0.99 for all the TCs and in the four trials. Errors were minor in all cases, but were more marked for the elbow used at high flow. In this trial, the temperature evolution showed a worst fit sigmoidly due to strong turbulence at the inlet. It is worth stressing that such cases are not usual in hot water tanks because stratification is favoured in such facilities. Table 3 presents the values of RMSE and Pearson's correlation coefficient $r$ in every experimental trial and for each TC during the charging process.

\subsection{Estimation of temperature values at any depth and time: the Virtual TC method}

The curves showing temperature at any point between the most superficial and the deepest thermocouples were obtained from the estimation by interpolation with the spline of the value of the five 5PL function parameters. Figure 9 presents the results of applying the Virtual TC method in the SBCD-L trial. Apart from the 12 curves fitted initially with the 5PL function depicted in red (the real thermocouples; Fig. 3), the curves interpolated at the positions where there was no real thermocouple (virtual thermocouples) are shown in blue. In the case illustrated in Fig. 9, 15 curves were interpolated between each pair of real consecutive thermocouples, represented as a total of $12+[15 \times 11]=177 \mathrm{TC}$. As it was possible to obtain the temperatures profile at any depth, the drawbacks relating to the availability of discrete temperature data discussed in [18] were avoided.

\subsection{Applying the Virtual TC method to temperature profile characterisation}

The Virtual TC procedure allows a more precise characterisation of temperature profile evolution inside a water tank because the temperature can be estimated accurately at any depth and any time throughout the charge process.

By way of example, Fig. 10 shows the instantaneous temperature profile at $t^{*}=0.6(60 \%$ of the total tank volume replaced), obtained with the experimental data from the SBCD-L trial. To obtain this profile, linear interpolation (LI) is done using the 12 temperature values provided by the TCs fitted in the tank (Fig. 10 left). Figure 10 (right) depicts the instantaneous temperature profile at $\mathrm{t}^{*}=0.6$ with the Virtual TC interpolation method using 177 values ( 12 real TC and 165 virtual ones). It can be stated that the temperature profile was better defined when the Virtual TC method was used, despite the same number of measuring points being employed in both cases. 


\subsection{Applying Virtual TC to estimate thermocline thickness}

In Fig.10, the point where the vertical dashed lines intersect with the instantaneous temperature profile indicates the position of the cut-off point ( $10 \%$ of each temperature profile end) and the temperature values considered to estimate thermocline thickness. As deduced from this figure, the thermocline thickness determined by the LI was thicker than that determined when the Virtual TC was applied. This is due to the reduced degree of accuracy of the cut-off point location, particularly on the lower limit where the change in temperature was more gradual. Consequently, the thermocline thickness estimate was more precise when the Virtual TC was used.

Figure 11 depicts the evolution of thermocline thickness throughout the loading process, determined by LI when the data provided by the 12 TC in the SBCD-L trial were used, and by the Virtual TC method with 177 data. Large differences between the two curves can be seen, which result from the number of points employed.

The values obtained by LI were always higher than those obtained with Virtual TC for the abovementioned reasons, and they also showed a characteristic oscillation. This oscillation was due to discrete data being employed (as there were a finite number of TCs available) to determine a parameter that varies continuously. Consequently, the thermocline thickness value estimated by $\mathrm{LI}$ at a given time depended on the exact instant at which it was calculated. The frequency of oscillation depended directly on the number of thermocouples. The larger the number of thermocouples employed, the less the amplitude was, and the oscillation became more frequent, which reduced estimation errors. When considering a very large number of thermocouples, the thermocline thickness estimated with Virtual TC presented a much more uniform pattern.

In the trials done with the diffuser with high flow (SBCD-H) and the elbow with low flow (E-L), similar results were obtained to those in the SBCD-L trial, which are shown in Fig. 11. Conversely in the trial done with an elbow with high flow (E-H), neither method (LI or Virtual TC) provided acceptable results owing to the turbulence generated at the inlet, which caused the mixing of water inside the water tank. In this case, the temperature evolution at each thermocouple presented no sigmoidal distribution that could be well fitted, particularly in the first TCs (Fig. 7). Therefore, this is not usually the case in a hot water tank, where stratification is normally favoured.

The oscillations that showed the thermocline thickness determined by LI seemed to indicate that the estimation error was much more serious than when determined with Virtual TC. The results obtained reveal that Virtual TC allowed the temporal evolution of thermocline thickness to be determined, while the estimation by LI would only be valid if a sufficient and very high number of measuring points were installed. As for the number of measuring points that are necessary, although [27] stated that the spacing between sensors must be equal to or less than the thermocline thickness, this was not always the case as it depended on the instant at which it was determined because, when LI was applied, very abrupt and major changes in the calculated thermocline thickness value took place in very short time intervals.

Figure 12 shows evolution of the thermocline thickness throughout the charge process as determined by the Virtual TC method in the four experimental trials.

The thermocline thickness in the E-H trial was much thicker than in the other three trials in which, as expected, it increased progressively as the charge time elapsed.

The thickness of the thermocline was greater in the E-L than in the SBCD-L trial, and the difference was maintained throughout the whole charging period. This difference was due 
exclusively to the turbulence by the inlet device, which became greater with the elbow than with the SBCD.

When comparing the two trials conducted with the SBCD, the more marked turbulence and greater thermocline thickness occurred at the beginning of the charge process in the trial done with higher flow. However, these differences diminished as the charge process continued until thermocline thickness became equal in both cases. This indicates that turbulence at the inlet did not affect the lower tank layers in which the thermocline advanced.

The differences in thermocline thickness evolution between the distinct trials, as determined by Virtual TC, were not detected or were less evident when other procedures to study the degree of stratification were employed, such as the fit with the four-parameter sigmoid function proposed by [18], or 1-MIX number as shown in [19].

In order to highlight the previously discussed results and dynamically prove the appropriateness and fitness of Virtual TC, two videos have been included. For the SBCD-L and E-L trials, these videos depict the evolution of the instantaneous temperature profile over time and the thermocline thickness throughout the charging process, as estimated by both LI and Virtual TC.

\section{CONCLUSIONS}

In this paper a new method has been developed, called Virtual TC, which enables water temperature to be estimated at any depth and time in a storage tank during charging. For this purpose, the distribution profile of the water temperature in a hot water storage tank was previously modelled from the experimental data. Four thermal charging experimental trials were carried out in a 950-L hot water tank provided with two different inlet devices (an elbow, $E$, and a sintered bronze conical diffuser, $S B C D$ ) at two distinct water flow rates (high, $\mathrm{H} ;$ low, L). The water temperature in the tank was recorded with 12 type T (Class 1 ) thermocouples (TCs) distributed uniformly along the vertical axis of the tank.

A five-parameter logistic (5PL) curve was successfully used to model the water temperature evolution at each TC location during the dimensionless charge time.

The estimation errors in temperature evolution at the position of each TC were very acceptable (RMSE between $0.2374^{\circ} \mathrm{C}$ and $0.9523^{\circ} \mathrm{C}$ on average in the SBCD-L and E-H experimental trials, respectively) and became less marked as the turbulence generated during the thermal charge process became lower.

The evolution of the five 5PL curve parameters with dimensionless depth showed a well-defined tendency. This allowed the value of each one to be estimated by interpolation with the cubic spline at any intermediate depth between two successive TCs, and with this the temperature value at any time and depth with the 5PL function, thus avoiding disadvantages related to the availability of discrete temperature data.

The methodology proposed in this paper is notably useful for calculating the numerous temperature-dependent indices used to characterise and evaluate thermal stratification in water storage tanks. As a practical example, this includes its application to determine the instantaneous temperature profile, and thermocline thickness and its evolution over time under experimental conditions.

It is concluded that the Virtual TC method provides very satisfactory results. It allows both temperature profiles and thermocline thickness evolution to be obtained throughout the thermal charge process with more spatial precision and temporal stability than other methods, such as linear interpolation of data from thermocouples or the fit with the four-parameter sigmoid function, under the normal operating conditions of hot water tanks. In this regard 
should be noted the substantial improvement of this methodology with respect to the linear interpolation, especially when a reduced number of thermocouples is available and with high capacity water storage tanks. The smaller the number of thermocouples used to obtain experimental data, the more advantageous the Virtual TC method is.

\section{ACKNOWLEDGEMENTS}

This research has been supported by the Plan Nacional de I+D+i del Ministerio de Ciencia $e$ Innovación (ENE2009-13376). The authors would like to thank L.H. Sanchis for his valuable ideas and constructive suggestions.

\section{REFERENCES}

[1] Y. Zurigat, A. Ghajar, Heat transfer and stratification in sensible heat storage systems, In: Dinçer, I., Rosen, M.A. (Eds.), Thermal Energy Storage. Systems and Applications. John Wiley \& Sons, New York. (2002) 259-301.

[2] K.G.T. Hollands, M.F. Lightstone, A review of low-flow stratified-tank solar water heating systems, Solar Energy. 43 (2) (1989) 97-105.

[3] C. Cristofari, G. Notton, P. Poggi, A. Louche, Influence of the flow rate and the tank stratification degree on the performances of a solar flat-plate collector, International Journal of Thermal Sciences. 42 (5) (2003) 455-469.

[4] U. Jordan, S. Furbo, Thermal stratification in small solar domestic storage tanks caused by draw-offs, Solar Energy. 78 (2) (2005) 291-300.

[5] Y.M. Han, R.Z. Wang, Y.J. Dai, Thermal stratification within the water tank, Renewable and Sustainable Energy Reviews. 13 (5) (2009) 1014-1026.

[6] R. Shukla, K. Sumathy, P. Erickson, J. Gong, Recent advances in the solar water heating systems: A review, Renewable and Sustainable Energy Reviews. 19 (0) (2013) 173-190.

[7] W. Yaïci, M. Ghorab, E. Entchev, S. Hayden, Three-dimensional unsteady CFD simulations of a thermal storage tank performance for optimum design, Applied Thermal Engineering. 60 (12) (2013) 152-163.

[8] M. Gasque, P. González-Altozano, D. Maurer, I.J. Moncho-Esteve, R.P. Gutiérrez-Colomer, G. Palau-Salvador, et al., Study of the influence of inner lining material on thermal stratification in a hot water storage tank, Applied Thermal Engineering. 75 (0) (2015) 344-356.

[9] A. Pizzolato, F. Donato, V. Verda, M. Santarelli, CFD-based reduced model for the simulation of thermocline thermal energy storage systems, Applied Thermal Engineering. 76 (0) (2015) 391-399. 
[10] M.Y. Haller, C.A. Cruickshank, W. Streicher, S.J. Harrison, E. Andersen, S. Furbo, Methods to determine stratification efficiency of thermal energy storage processes - Review and theoretical comparison, Solar Energy. 83 (10) (2009a) 1847-1860.

[11] A. Castell, M. Medrano, C. Solé, L.F. Cabeza, Dimensionless numbers used to characterize stratification in water tanks for discharging at low flow rates, Renewable Energy. 35 (10) (2010) 2192-2199.

[12] A. Mawire, S.H. Taole, A comparison of experimental thermal stratification parameters for an oil/pebble-bed thermal energy storage (TES) system during charging, Applied Energy. 88 (12) (2011) 4766-4778.

[13] V. Panthalookaran, W. Heidemann, H. Müller-Steinhagen, A new method of characterization for stratified thermal energy stores, Solar Energy. 81 (8) (2007) 1043-1054.

[14] J. Yoo, M. Wildin, C. Truman, Initial formation of a thermocline in stratified thermal storage tanks, ASHRAE Transactions. 92 (2A) (1986) 280-292.

[15] A. Musser, W.P. Bahnfleth, Evolution of temperature distributions in a full-scale stratified chilled-water storage tank with radial diffusers, ASHRAE Transactions. 104 (1) (1998) 1-13.

[16] W.P. Bahnfleth, J. Song, Constant flow rate charging characteristics of a full-scale stratified chilled water storage tank with double-ring slotted pipe diffusers, Applied Thermal Engineering. 25 (17) (2005) 3067-3082.

[17] J.D. Chung, S.H. Cho, C.S. Tae, H. Yoo, The effect of diffuser configuration on thermal stratification in a rectangular storage tank, Renewable Energy. 33 (10) (2008) 2236-2245.

[18] J. Waluyo, M.A.A. Majid, Temperature Profile and Thermocline Thickness Evaluation of a Stratified Thermal Energy Storage Tank. International Journal of Mechanical \& Mechatronics Engineering. 10 (1) (2010) 7-12.

[19] E. García-Marí, M. Gasque, R.P. Gutiérrez-Colomer, F. Ibáñez, P. González-Altozano, A new inlet device that enhances thermal stratification during charging in a hot water storage tank, Applied Thermal Engineering. 61 (2) (2013) 663-669.

[20] Matlab, Version 7.13. 0.564 (R2011b). The MathWorks, (2011).

[21] R. Bayón, E. Rojas, Analytical function describing the behaviour of a thermocline storage tank: A requirement for annual simulations of solar thermal power plants, International Journal of Heat and Mass Transfer. 68 (0) (2014) 641-648.

[22] J.H. Ricketts, G.A. Head, A five-parameter logistic equation for investigating asymmetry of curvature in baroreflex studies, The American Journal of Physiology. 277 (2 Pt 2) (1999) R441R454.

[23] F. Richards, A flexible growth function for empirical use, Journal of experimental botany. 10 (2) (1959) 290-301.

[24] R.A. Dudley, P. Edwards, R.P. Ekins, D.J. Finney, I.G. McKenzie, G.M. Raab, et al., Guidelines for immunoassay data processing, Clinical chemistry. 31 (8) (1985) 1264-1271. 
[25] P.G. Gottschalk, J.R. Dunn, The five-parameter logistic: A characterization and comparison with the four-parameter logistic, Analytical Biochemistry. 343 (1) (2005) 54-65.

[26] S. Wold, Spline functions in data analysis, Technometrics. 16 (1) (1974) 1-11.

[27] W.P. Bahnfleth, A. Musser, Thermal performance of a full-scale stratified chilled-water thermal storage tank, TRANSACTIONS-AMERICAN SOCIETY OF HEATING REFRIGERATING AND AIR CONDITIONING ENGINEERS. 104 (1998) 377-388.

[28] M. Haller, W. Streicher, E. Andersen, S. Furbo, Compararative Analysis of Thermal Energy Storage Stratification Efficiency-A New Method Combines Advantages of Previous Approaches, 11th international conference on thermal energy storage for efficiency and sustainability. Stockholm, June, 14-17. (2009b) 1-9. 


\section{NOMENCLATURE}

4PL: Four-parameter logistic

5PL: Five-parameter logistic

a: Temperature of the lower asymptote $\left({ }^{\circ} \mathrm{C}\right)$

$\boldsymbol{b}$ : Temperature of the upper asymptote $\left({ }^{\circ} \mathrm{C}\right)$

$c$ : Dimensionless time position of the transition region

$d$ : Slope of the curve's transition region

E: Conventional inlet elbow

$\boldsymbol{g}$ : Parameter that permits asymmetry to be effectively modelled

$\mathrm{H}$ : High flow $\left(L \cdot \mathrm{min}^{-1}\right)$

LI: Linear interpolation

L: Low flow $\left(L \cdot \mathrm{min}^{-1}\right)$

$\mathrm{n}$ : Number of observations

$r$ : Pearson's correlation coefficient

RMSE: Root Mean Square Error $\left({ }^{\circ} \mathrm{C}\right)$

SBCD: Sintered bronze conical diffuser

$\mathrm{t}^{*}$ : Dimensionless time

$\mathrm{T}$ : Temperature $\left({ }^{\circ} \mathrm{C}\right)$

$\mathrm{T}_{\mathrm{c}}$ : Average inlet temperature $\left({ }^{\circ} \mathrm{C}\right)$

$\mathrm{T}_{\mathrm{f}}$ : Last temperature value recorded for each thermocouple $\left({ }^{\circ} \mathrm{C}\right)$

$\mathrm{T}_{\mathrm{h}}$ : Initial bulk temperature $\left({ }^{\circ} \mathrm{C}\right)$

$T_{\text {ini: }}$ First temperature value recorded for each thermocouple $\left({ }^{\circ} \mathrm{C}\right)$

TC: Thermocouple

$\mathrm{x}$ : Dimensionless charging time

$\mathrm{x}_{\mathrm{i}}$ : Experimental values of $\mathrm{T}$

$\hat{\mathrm{X}}_{\mathrm{i}}$ : Estimated values of $\mathrm{T}$

$\mathrm{Z}_{\mathrm{TC}}$ : Dimensionless depth at which TC is located

Greek letters

$\Theta$ : Dimensionless temperature 


\section{LIST OF FIGURE CAPTIONS}

Fig. 1: Schematic view of the experimental setup.

Fig. 2: Picture of the experimental facility.

Fig. 3: Characteristic trend of the temperature evolution recorded by each TC (e.g. the SBCD-L trial).

Fig. 4: Temperature evolution recorded by each TC in cases with a greater mix and destratification at the top of the tank (e.g., the E-H trial).

Fig. 5: Values of the 5PL function parameters at the dimensionless height of each TC in the E-H trial. Left: fixing parameters $\boldsymbol{a}$ and $\boldsymbol{b}$. Right: fixing $\boldsymbol{a}, \boldsymbol{b}$ and $\boldsymbol{c}$.

Fig. 6: Temperature evolution in each TC. Experimental data (SBCD-L trial) and the fitted 5PL function.

Fig. 7: Temperature evolution in each TC. Experimental data (E-H trial) and the fitted 5PL function.

Fig. 8: The SBCD-L trial values for the five 5PL function parameters at the dimensionless height of each TC and interpolation with the spline.

Fig. 9: Temperature evolution in the SBCD-L trial. Experimental data and Virtual TC.

Fig. 10: Instant temperature profile at $t^{*}=0.6$ (60\% of the total tank volume replaced) in the SBCD-L trial. Left: linear interpolation done with the values recorded by the $12 \mathrm{TC}$. Right: applying Virtual TC with 177 data (12 real TC and 165 virtual ones).

Fig. 11: Thermocline thickness evolution in the SBCD-L trial. Determination by linear interpolation (LI) from the 12 thermocouples fitted in the tank (real TC) and determination by the Virtual TC method using 177 thermocouples (12 real TC and 165 virtual ones).

Fig. 12: Thermocline thickness throughout the charge process as determined by the Virtual TC method in the four experimental trials. 


\section{LIST OF TABLE CAPTIONS}

Table 1: Trials conducted.

Table 2: Initial values and variation ranges of the five parameters used to fit the 5PL function in each TC.

Table 3: Validation of Virtual TC model 


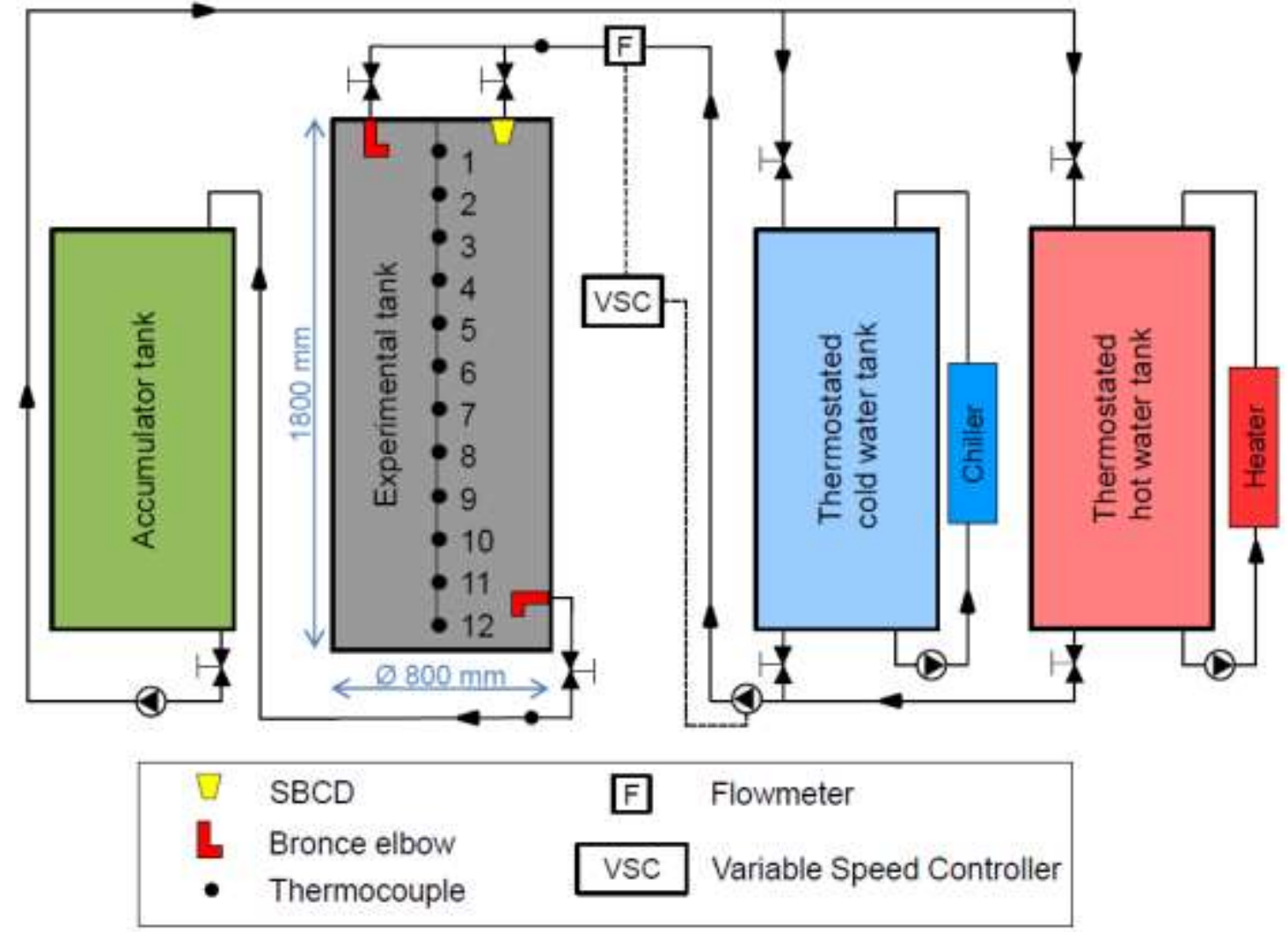

Fig. 1: Schematic view of the experimental setup. 


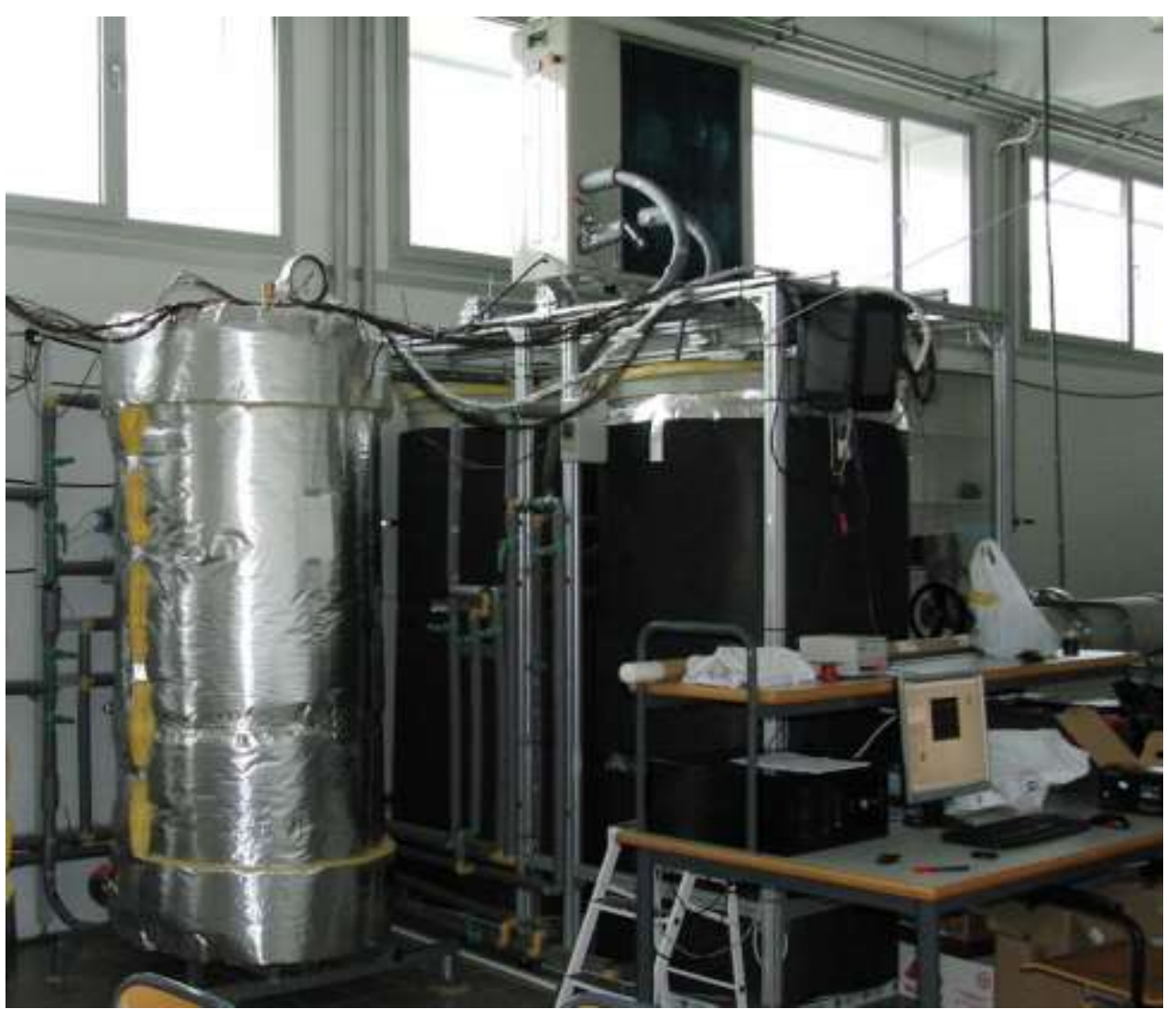

Fig. 2: Picture of the experimental facility. 


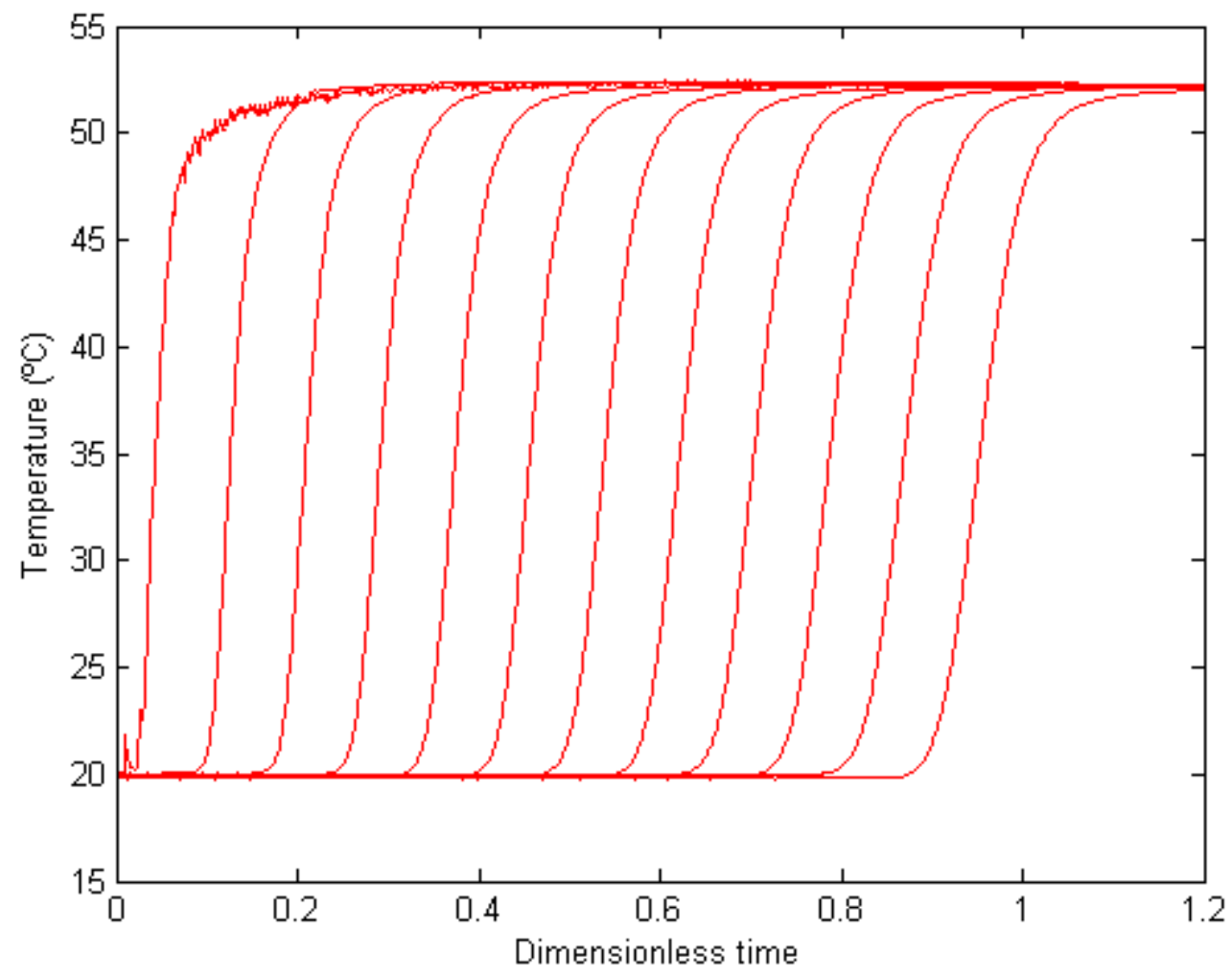

Fig. 3: Characteristic trend of the temperature evolution recorded by each TC (e.g. the SBCD-L trial). 


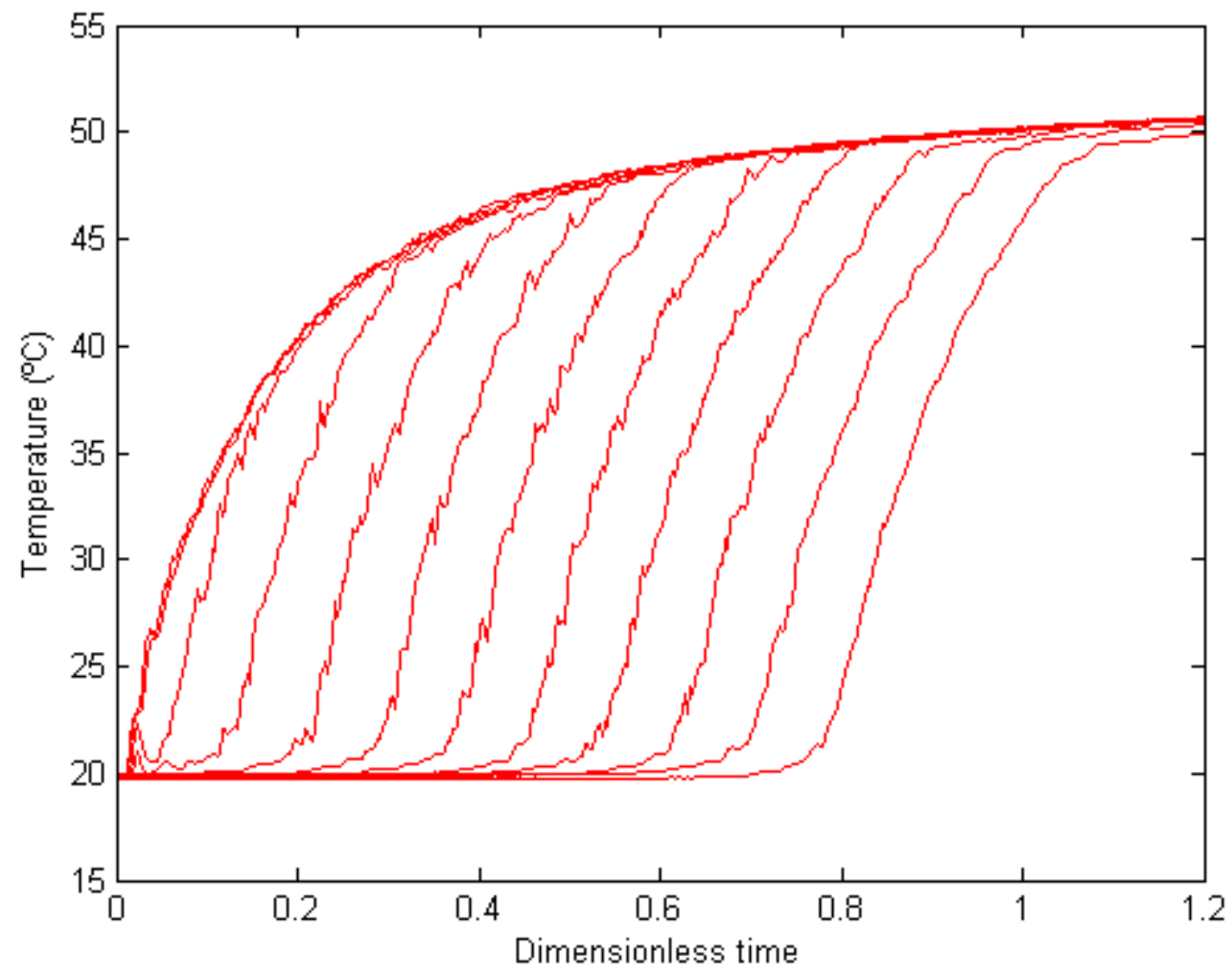

Fig. 4: Temperature evolution recorded by each TC in cases with a greater mix and destratification at the top of the tank (e.g., the E-H trial). 

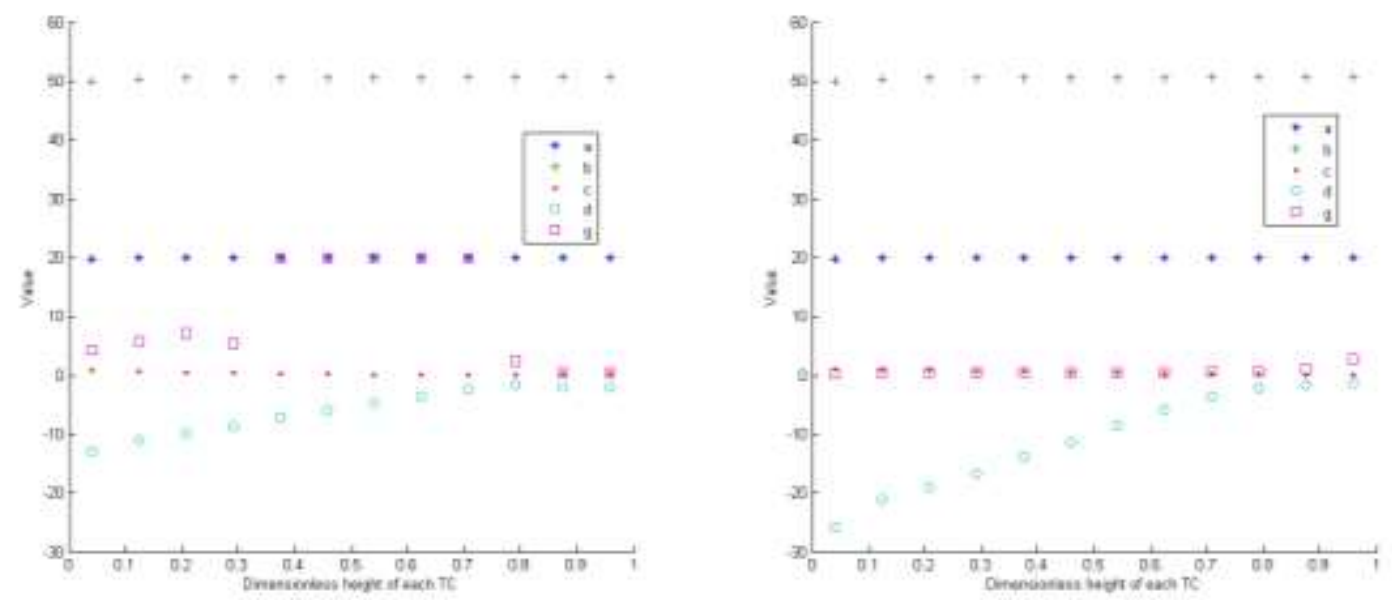

Fig. 5: Values of the 5PL function parameters at the dimensionless height of each TC in the E-H trial. Left: fixing parameters $\boldsymbol{a}$ and $\boldsymbol{b}$. Right: fixing $\boldsymbol{a}, \boldsymbol{b}$ and $\boldsymbol{c}$. 


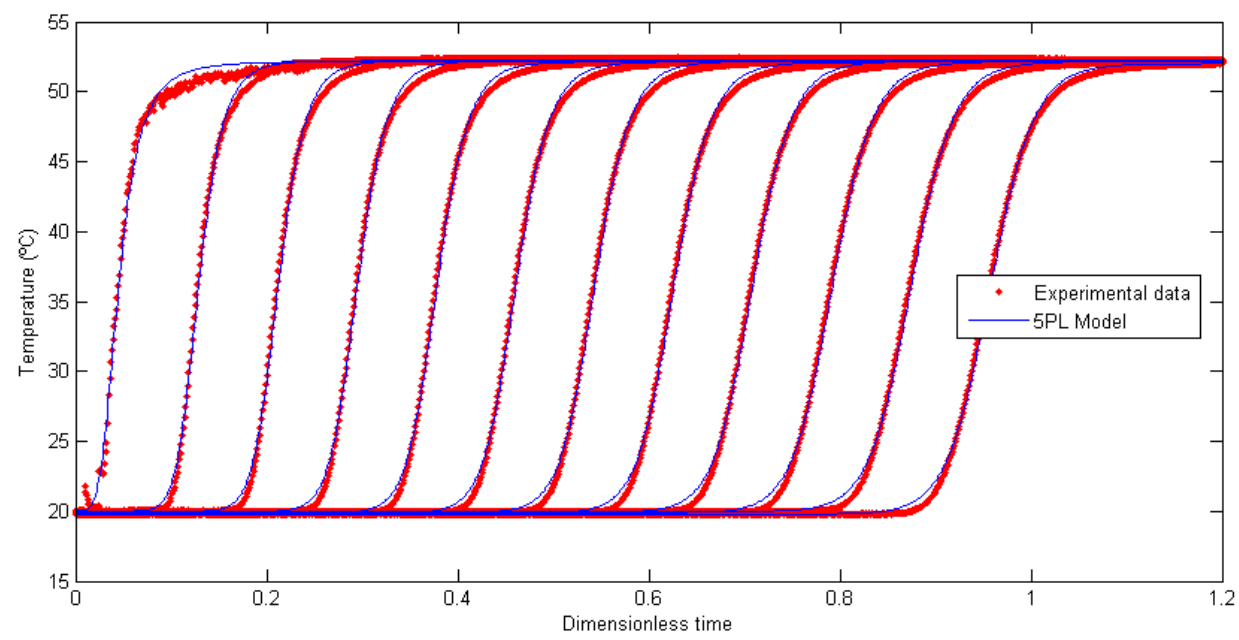

Fig. 6: Temperature evolution in each TC. Experimental data (SBCD-L trial) and the fitted 5PL function. 


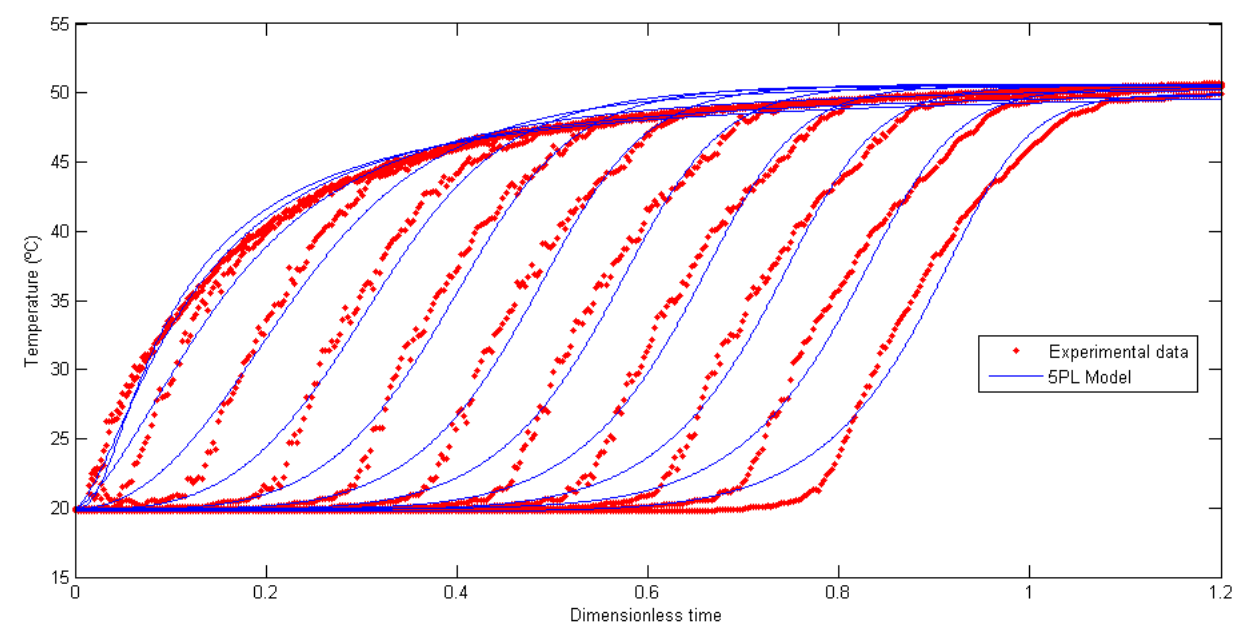

Fig. 7: Temperature evolution in each TC. Experimental data (E-H trial) and the fitted 5PL function. 


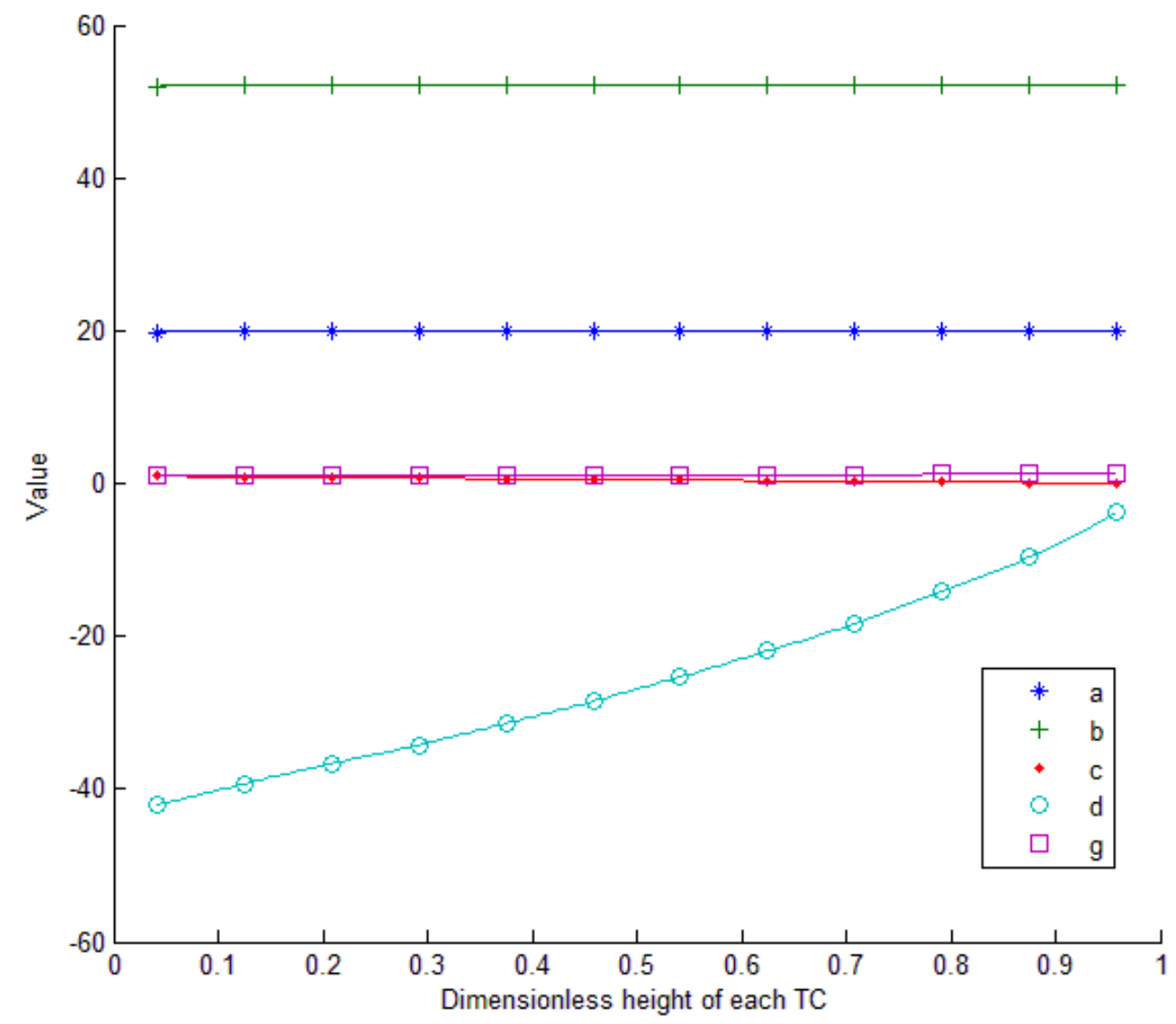

Fig. 8: The SBCD-L trial values for the five 5PL function parameters at the dimensionless height of each TC and interpolation with the spline. 


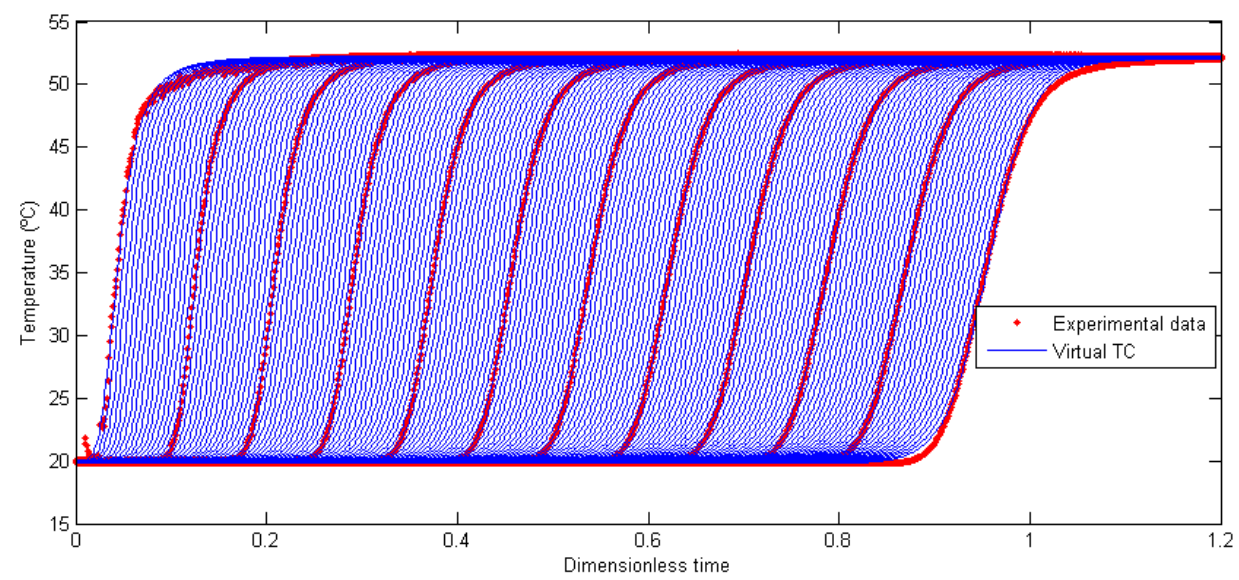

Fig. 9: Temperature evolution in the SBCD-L trial. Experimental data and Virtual TC. 

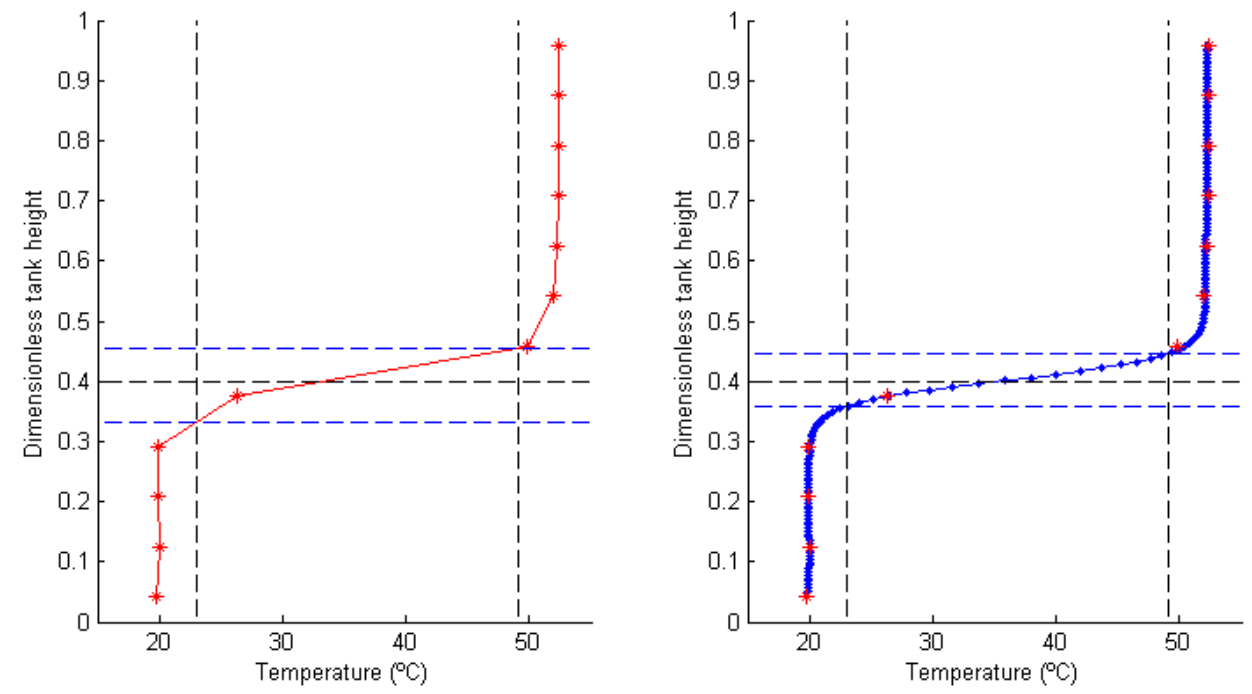

Fig. 10: Instant temperature profile at $t^{*}=0.6$ (60\% of the total tank volume replaced) in the SBCD-L trial. Left: linear interpolation done with the values recorded by the $12 \mathrm{TC}$. Right: applying Virtual TC with 177 data (12 real TC and 165 virtual ones). 


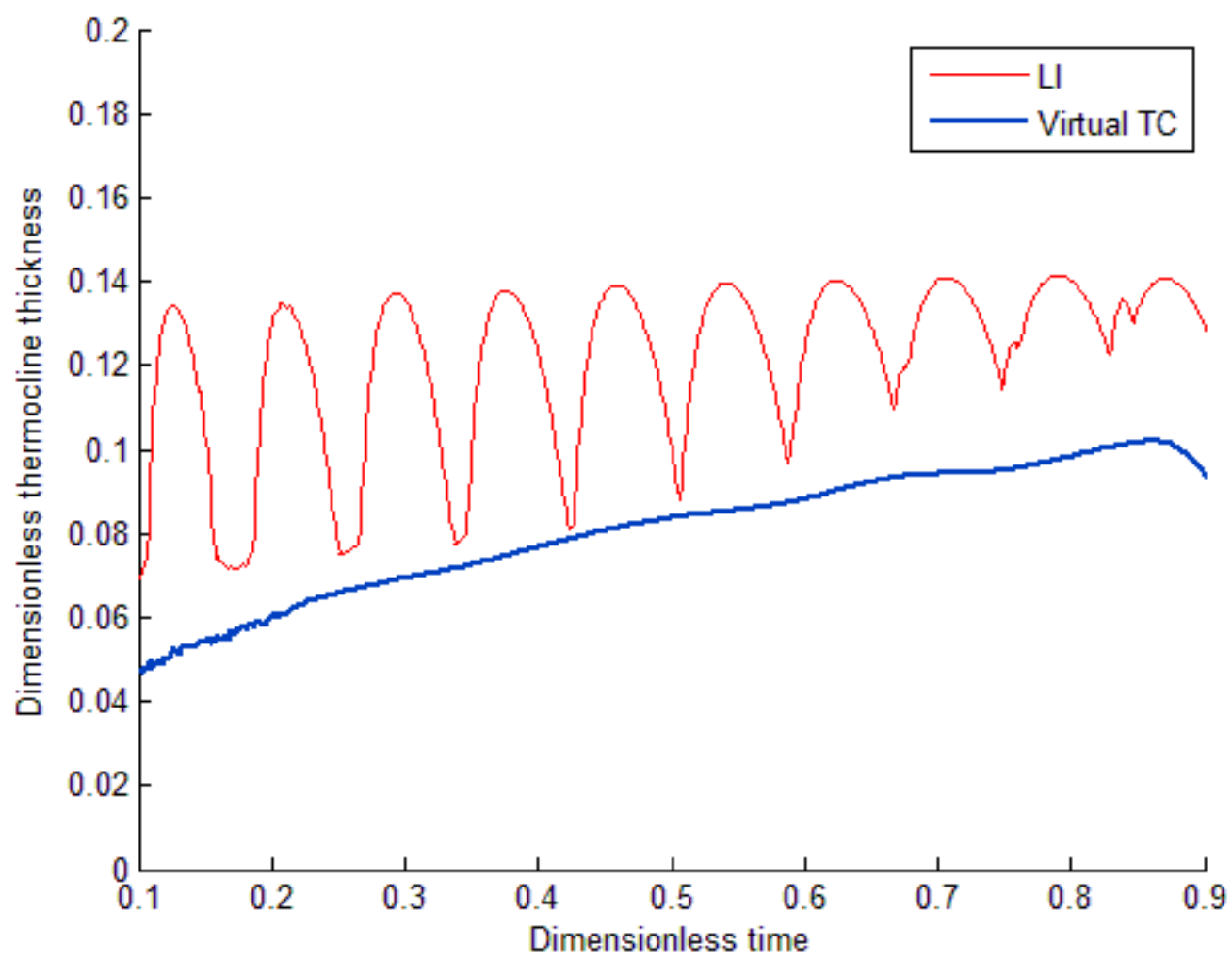

Fig. 11: Thermocline thickness evolution in the SBCD-L trial. Determination by linear interpolation (LI) from the 12 thermocouples fitted in the tank (real TC) and determination by the Virtual TC method using 177 thermocouples (12 real TC and 165 virtual ones). 


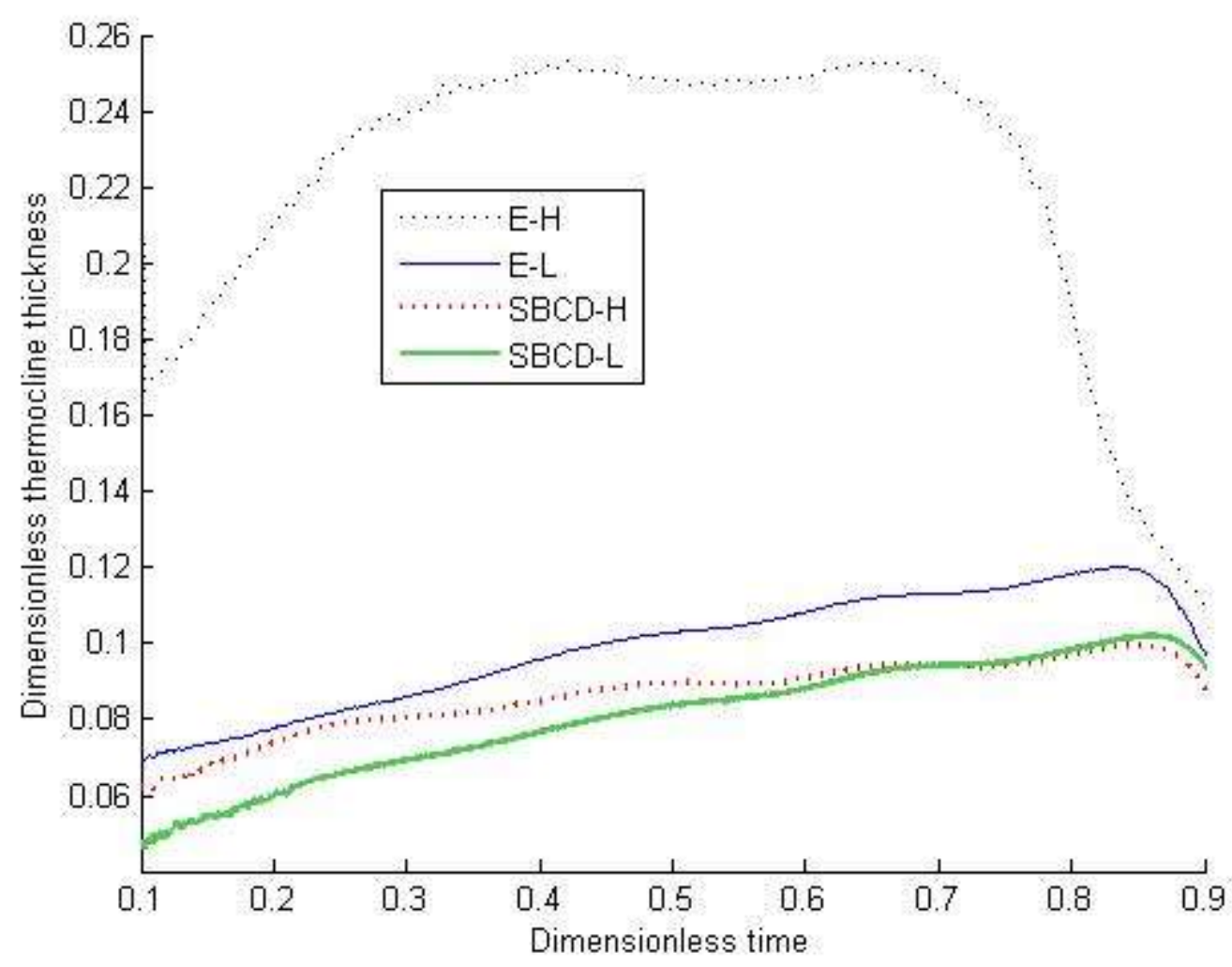

Fig. 12: Thermocline thickness throughout the charge process as determined by the Virtual TC method in the four experimental trials. 
Table 1: Trials conducted.

\begin{tabular}{lc}
\hline Trial & Flow $\left(\mathbf{L} \cdot \mathbf{m i n}^{-1}\right)$ \\
\hline \hline SBCD-L & 6 \\
SBCD-H & 16 \\
\hline E-L & 6 \\
E-H & 16 \\
\hline
\end{tabular}

E: Elbow. SBCD: Sintered Bronze Conical Diffuser. $\mathrm{H}, \mathrm{L}$ : high and low water flow, respectively. 
Table 2: Initial values and variation ranges of the five parameters used to fit the 5PL function in each TC.

\begin{tabular}{|c|c|c|c|}
\hline Parameter & Initial Value & Minimum & Maximum \\
\hline $\boldsymbol{a}$ & 20 & $\mathrm{~T}_{\mathrm{ini}}$ & $\mathrm{T}_{\mathrm{ini}}+0.0001$ \\
\hline $\boldsymbol{b}$ & 52 & $\mathrm{~T}_{\mathrm{f}}$ & $\mathrm{T}_{\mathrm{f}}+0.0001$ \\
\hline $\boldsymbol{c}$ & $\mathrm{Z}_{\mathrm{TC}}$ & $\mathrm{Z}_{\mathrm{TC}}$ & $\mathrm{Z}_{\mathrm{TC}}+0.0001$ \\
\hline $\boldsymbol{d}$ & -25 & -50 & 0 \\
\hline $\boldsymbol{g}$ & 0.7 & 0 & 20 \\
\hline
\end{tabular}

$\mathrm{T}_{\text {ini: }}$ Initial temperature, first temperature value recorded for $\mathrm{TC}\left({ }^{\circ} \mathrm{C}\right)$. $\mathrm{T}_{\mathrm{f}}$ : Final temperature, last temperature value recorded for $\mathrm{TC}\left({ }^{\circ} \mathrm{C}\right)$. $\mathrm{Z}_{\mathrm{TC}}$ : Dimensionless depth at which $\mathrm{TC}$ is located. 
Table 3: Validation of Virtual TC model

\begin{tabular}{lcccccc}
\hline & RMSE (ㄷ) & RMSE (ㅇ) & RMSE (ㅇ) & $\mathbf{r}$ & $\mathbf{r}$ & $\mathbf{r}$ \\
\cline { 2 - 7 } Trial & Max & Min & Mean & Max & Min & Mean \\
\hline \hline SBCD-L & 0,3525 & 0,2065 & 0,2374 & 0,9999 & 0,9981 & 0,9997 \\
SBCD-H & 0,4861 & 0,2726 & 0,4197 & 0,9997 & 0,9986 & 0,9995 \\
\hline E-L & 0,6934 & 0,2500 & 0,5075 & 0,9995 & 0,9976 & 0,9992 \\
E-H & 1,1627 & 0,5358 & 0,9523 & 0,9978 & 0,9932 & 0,9966 \\
\hline
\end{tabular}

E: Elbow. SBCD: Sintered Bronze Conical Diffuser. $H$, L: high and low water flow, respectively. RMSE: Root Mean Square Error.

$r$ : Pearson's correlation coefficient. 